Proc. of the International Conference on Mechanochemistry and Mechanical Alloying, Kraków, Poland, June 22-26, 2014

\title{
Mechanochemical Synthesis of Silver Chloride Nanoparticles by a Dilution Method in the System $\mathrm{NH}_{4} \mathrm{Cl}-\mathrm{AgNO}_{3}-\mathrm{NH}_{4} \mathrm{NO}_{3}$
}

\author{
B.B. TAtykaev ${ }^{a, *}$, M.M. Burkitbayev ${ }^{a}$, B.M. Uralbekov ${ }^{a}$ And F.Kh. Urakaev ${ }^{b}$ \\ ${ }^{a}$ Al-Farabi Kazakh National University, Al-Farabi Av., 71, Almaty 050040, Kazakhstan \\ ${ }^{b}$ V.S. Sobolev Institute of Geology and Mineralogy SB RAS, Acad. Koptyug Av., 3, Novosibirsk 630090, Russia
}

\begin{abstract}
This study presents the results of the synthesis of silver chloride nanoparticles dispersed within ammonium nitrate matrix via displacement mechanochemical reaction $\mathrm{NH}_{4} \mathrm{Cl}+\mathrm{AgNO}_{3}+z \mathrm{NH}_{4} \mathrm{NO}_{3}=(z+1) \mathrm{NH}_{4} \mathrm{NO}_{3}+\mathrm{AgCl}$ at $z=z_{1}=7.22$ and $z=z_{2}=3.64$. The intermediate compound, $\mathrm{NH}_{4} \mathrm{Ag}\left(\mathrm{NO}_{3}\right)_{2}$, was identified after mechanochemical processing of studied system. Use of simultaneous thermogravimetry and differential scanning calorimetry provide a new means for preparing silver chloride nanoparticles in their free form by thermal treatment.
\end{abstract}

DOI: 10.12693/APhysPolA.126.1044

PACS: 81.07.Wx, 81.07.-b

\section{Introduction}

Silver halides are used in a various fields as photomaterials, catalytic materials and semiconductors. It is well known that powder in nanoscale structure can be characterized by properties that differ from those of bulk materials. Many methods have been developed such as sol-gel techniques, in situ synthesis, microemulsion methods and liquid crystalline phase reaction to prepare nanoparticles, including silver halides. At present, two methods have been proposed to prepare silver halides by mechanochemical processing. In the first case $[1,2]$ silver iodide has been obtained by separation from water solution following long mechanical milling of $\mathrm{AgI}$ in planetary mill. In the second case [3] nanoscale $\mathrm{Ag}_{1-x} \mathrm{Cu}_{x} \mathrm{I}$ crystals were prepared by using soft mechanochemical reaction of iodine, copper and silver.

In this study, the focus is put on the preparation of silver chloride nanoparticles using a mechanochemical method, pioneered by McCormick et al. [4, 5]. The method involves a mechanochemically induced solid-state reaction, where synthesized nanocrystalline particles are dispersed within a soluble salt matrix [6-12].

\section{Experimental}

The reagent used in this study were analytical pure of $\mathrm{AgNO}_{3}, \mathrm{NH}_{4} \mathrm{Cl}$ powders and $\mathrm{NH}_{4} \mathrm{NO}_{3}$ as a diluent. Soft mechanochemical reaction (MCR) of starting reactants by grinding in an agate mortar and milling in laboratory rotary mill is used to prepare silver chloride via the reaction $\mathrm{NH}_{4} \mathrm{Cl}+\mathrm{AgNO}_{3}+z \mathrm{NH}_{4} \mathrm{NO}_{3}=$ $(z+1) \mathrm{NH}_{4} \mathrm{NO}_{3}+\mathrm{AgCl}$. The main parameters such as

*corresponding author; e-mail: batuhan_tatykaew@mail.ru kinematics and dynamics of rotary mill have been presented elsewhere [12]. Dilution parameters z are calculated from equations of the form $[9,13]$ :

$$
\begin{aligned}
& z_{1}=\rho_{3}\left[\rho_{2} M_{1}-0.0937 \rho_{1} M_{2}\right] / 0.0937 \rho_{1} \rho_{2} M_{3}=7.22, \\
& z_{2}=2.28 \rho_{3}\left(\rho_{2} M_{1}+\rho_{1} M_{2}\right) / \rho_{1} \rho_{2} M_{3}=3.64,
\end{aligned}
$$

where $M_{i}$ and $\rho_{i}$ are the molecular weights and densities of the starting components $\left(i=1, \mathrm{NH}_{4} \mathrm{Cl}, M_{1}=53.49\right.$, $\left.\rho_{1}=1.53 \mathrm{~g} / \mathrm{cm}^{3} ; i=2, \mathrm{AgNO}_{3}, 169.87,4.35\right)$ and $\left(i=3, \mathrm{NH}_{4} \mathrm{NO}_{3}, 80.04,1.72\right)$. The physical properties, especially hardness of the initial reagents $\left(h\left(\mathrm{NH}_{4} \mathrm{Cl}\right)\right.$ and $\left.h\left(\mathrm{AgNO}_{3}\right)\right)$ as well as the diluent $\left(h\left(\mathrm{NH}_{4} \mathrm{NO}_{3}\right)\right.$ should be taken in consideration in order to find optimum dilution parameter for a given reaction. The optimum dilution parameter corresponds to Eq. (1) in case hardness of diluent is equal or higher than the rest starting reactants. In contrast, the optimum dilution parameter corresponds to Eq. (2) in case hardness of the diluent is lower than the rest starting reactants $h\left(\mathrm{NH}_{4} \mathrm{Cl}\right) \approx h\left(\mathrm{AgNO}_{3}\right)>$ $h\left(\mathrm{NH}_{4} \mathrm{NO}_{3}\right)$. In this study both parameters were used as the hardness for $\mathrm{AgNO}_{3}$ is not available in the literature.

Grinding in an agate mortar. The system components were subjected to grinding at $z=z_{2}$ for $30 \mathrm{~min}$ in an agate mortar. Mass of the initial components: $m_{1}=$ $70.2 \mathrm{mg}, m_{2}=224.6 \mathrm{mg}, m_{3}=381 \mathrm{mg}$.

Milling in laboratory rotary mill. The experiment was conducted at $z=z_{1}$ for 4 hours in laboratory rotary mill at $120 \mathrm{rpm}$. A cylindrical porcelain drum (outer diameter $8.54 \mathrm{~cm}$, volume $300 \mathrm{~cm}^{3}$ ) was used with ceramic cylpebs (46 cylinders with rounded ends: diameter $1.25 \mathrm{~cm}$, height $1.32 \mathrm{~cm}$, with an average weight of $7.62 \mathrm{~g})$. The total load weight including cylpebs was 350.49 g. Samples of the staring reactants were $m_{1}=467 \mathrm{mg}, m_{2}=1484 \mathrm{mg}, m_{3}=5049 \mathrm{mg}$, batch $m=7000 \mathrm{mg}$.

Thermogravimetry (TG) and differential scanning calorimetry (DSC) curves in dry nitrogen were prepared using a thermoanalyzer (NETZSCH 449F3A-0372-M) 
over the temperature range of $20-1000^{\circ} \mathrm{C}$. The parameters during measurements were as follows: crucible of $\mathrm{DSC} / \mathrm{TG}$ pan $\mathrm{Al}_{2} \mathrm{O}_{3}$; heating rate $10 \mathrm{~K} \mathrm{~min}^{-1}$. The empty $\mathrm{Al}_{2} \mathrm{O}_{3}$ pan was used as reference. Temperature calibration used a reference set of metals $(\mathrm{In}, \mathrm{Cu}, \mathrm{Zn})$ with known melting points.

X-ray diffraction (XRD) measurements of the powder were studied with D8 ADVANCE (Bruker AXS) X-ray powder diffractometer with $\mathrm{Cu} K_{\alpha}$ radiation in the $2 \theta$ range from $10^{\circ}$ to $60^{\circ}$ with $0.02^{\circ}$ step. Preliminary analysis of angle orientation, reflex intensity and phase composition were done by using EVA.exe software and PCPDFWIN with database PDF-2. Semiquantitative analyses of phase composition were carried out by method of Reference Intensity Ratio. Crystallite size was determined from the full-width at half maximum of the $\mathrm{X}$-ray spectrum using a Scherrer formula [14].

Surface morphology of particles was examined using FEI QUANTA 3D dual beam scanning electron microscope (SEM).

\section{Results and discussion}

The experiments and XRD analysis along with SEM examination revealed formation of silver chloride through solid-state chemical reaction by means of mechanochemical processing. The data obtained from simultaneous TG and DSC measurements provide an important information on presence of all components in stud- ied system of $\mathrm{NH}_{4} \mathrm{Cl}+\mathrm{AgNO}_{3}+z \mathrm{NH}_{4} \mathrm{NO}_{3}=$ $(z+1) \mathrm{NH}_{4} \mathrm{NO}_{3}+\mathrm{AgCl}$.

\subsection{Thermal analysis of components}

Typical TG and DSC curves of system components at different heating rates are shown in Fig. 1:

- ammonium chloride (Fig. 1a) - two well-developed endothermic peaks correspond to orientation phase changes [15] and sublimation at $T \approx 340{ }^{\circ} \mathrm{C}$;

- silver nitrate has several phase changes, melting at $T \approx 210{ }^{\circ} \mathrm{C}$, while higher than $300^{\circ} \mathrm{C}$ decaying according to the reaction $\mathrm{AgNO}_{3}=\mathrm{Ag}+\mathrm{NO}_{2}+\mathrm{O}_{2}$, the endothermic peak at $T \approx 960{ }^{\circ} \mathrm{C}$ corresponds to the melting of silver (Fig. 1b);

- ammonium nitrate, several endothermic peaks are resolved in the DSC curves for all heating rates, but the main peak at $\approx 320^{\circ} \mathrm{C}$ corresponds to the peak temperature of decomposition into gases (Fig. 1c);

- silver chloride decomposes over time with exposure to light, but characterised by thermal stability, melting point at $\approx 455^{\circ} \mathrm{C}$ (Fig. 1d), with boiling indicated at $\approx 1550{ }^{\circ} \mathrm{C}$.

Distinguishing the properties of non-soluble product $(\mathrm{AgCl})$ from other components can provide a means for selective removal of silver chloride by washing the resulting powder with appropriate solvents [6-11] or by selective heat treatment [16].
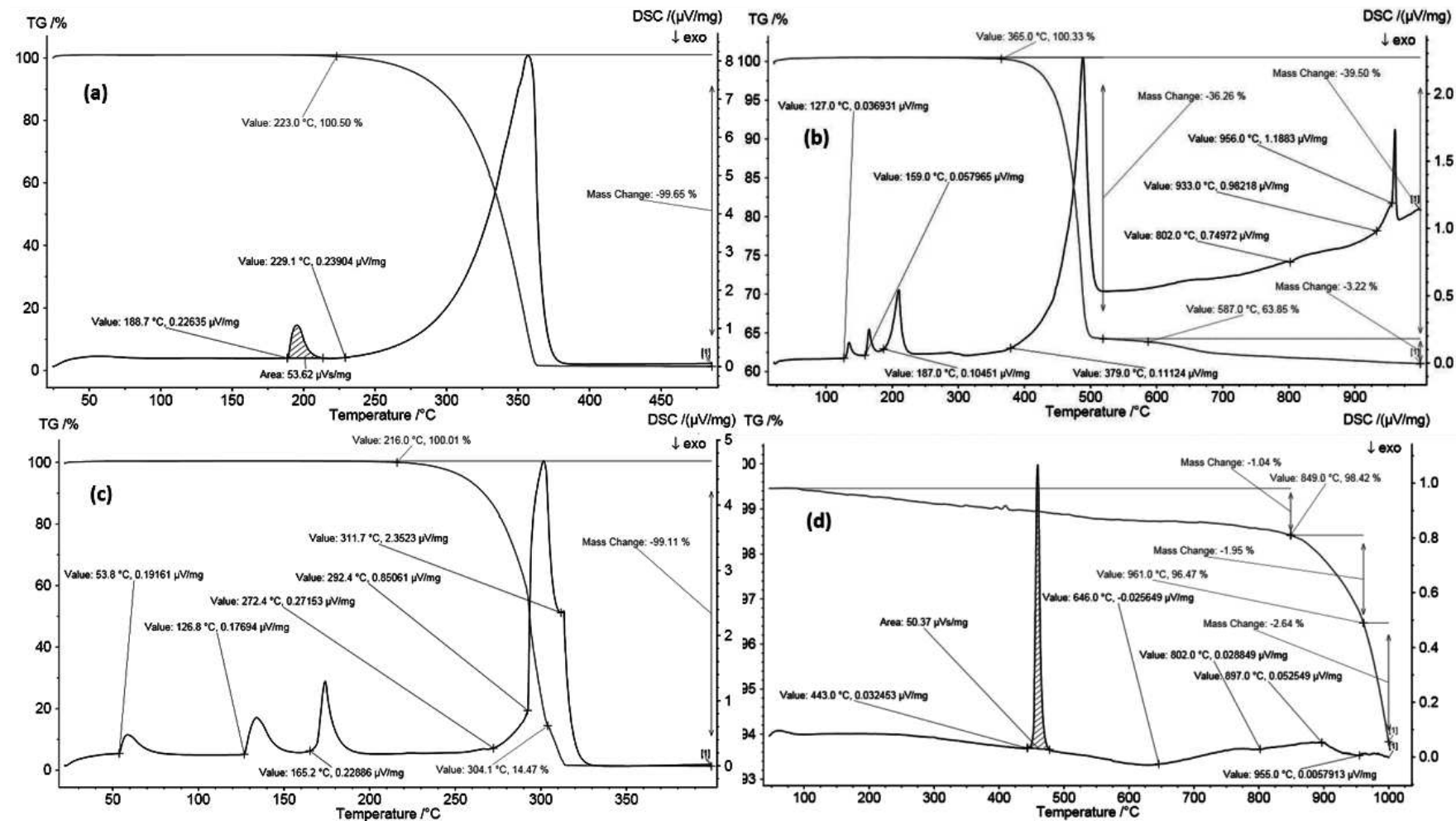

Fig. 1. TG/DSC curves for system components: (a) $\mathrm{NH}_{4} \mathrm{Cl}$, (b) $\mathrm{AgNO}_{3}$, (c) $\mathrm{NH}_{4} \mathrm{NO}_{3}$, (d) AgCl (powder obtained from water solution). 


\subsection{Soft mechanochemical reactions}

Figure 2a shows the XRD patterns of obtained products in a mortar via soft mechanochemical reaction (MCR). Identified reflexes for studied system correspond to following phases: $\mathrm{NH}_{4} \mathrm{NO}_{3}-74.9 \%$, $\mathrm{AgCl}-12.6 \%,\left(\mathrm{NH}_{4}\right) \mathrm{Ag}\left(\mathrm{NO}_{3}\right)_{2}-6.6 \%, \mathrm{AgNO}_{3}-$ $3.0 \%, \mathrm{NH}_{4} \mathrm{Cl}-2.9 \%$. These results suggest that soft MCR leads to formation of intermediate product $\left(\mathrm{NH}_{4}\right) \mathrm{Ag}\left(\mathrm{NO}_{3}\right)_{2}$, the properties of which have been presented elsewhere [17]. The crystallite size $(L)$ and crystal lattice microstrain $(\varepsilon)$ of $\mathrm{AgCl}$ estimated from XRD diagram (Fig. 2a) are found to be $132 \mathrm{~nm}$ and $0.2 \%$, respectively. Thermal analyses of soft MCR products are presented in Fig. 3a (next page). Simultaneous measurements of TG and DSC of MCR products show a set of endothermic characteristic peaks related to various phase changes and decomposition of the reactants as well as products.

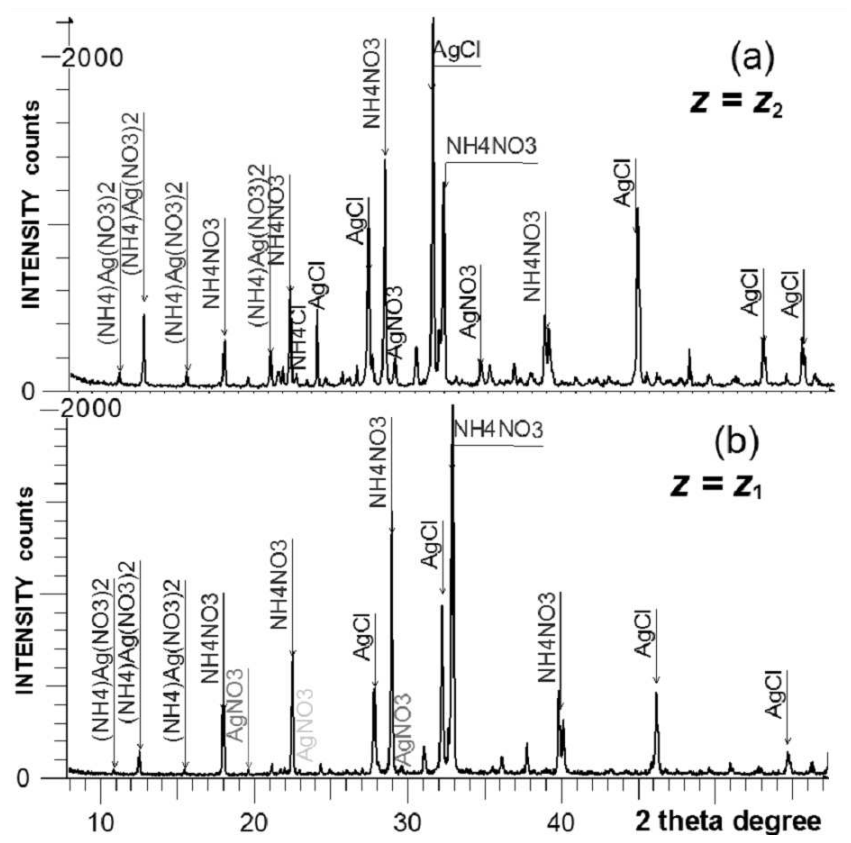

Fig. 2. X-ray diffraction patterns in the range $2 \theta=$ $4 \div 96^{\circ}$ of samples after MCR: (a) grinding in a mortar, (b) grinding in laboratory mill.

Figure $2 \mathrm{~b}$ shows the XRD of obtained products in a laboratory rotating mill via solid-state displacement reaction $\mathrm{NH}_{4} \mathrm{Cl}+\mathrm{AgNO}_{3}+z \mathrm{NH}_{4} \mathrm{NO}_{3}=(z+$ 1) $\mathrm{NH}_{4} \mathrm{NO}_{3}+\mathrm{AgCl}$ at $z=z_{1}$. Identified reflexes for studied system correspond to the following phases: $\mathrm{NH}_{4} \mathrm{NO}_{3}-88.8 \%, \mathrm{AgCl}-6.9 \%,\left(\mathrm{NH}_{4}\right) \mathrm{Ag}\left(\mathrm{NO}_{3}\right)_{2}-$ $2.2 \%, \mathrm{AgNO}_{3}-1.1 \%, \mathrm{NH}_{4} \mathrm{Cl}-1.0 \%$. These results also suggest that MCR did not go to completion. The crystallite size $(L)$ and crystal lattice microstrain $(\varepsilon)$ of $\mathrm{AgCl}$ estimated from XRD pattern (Fig. 2b) are found to be $151 \mathrm{~nm}$ and $0.18 \%$, respectively.
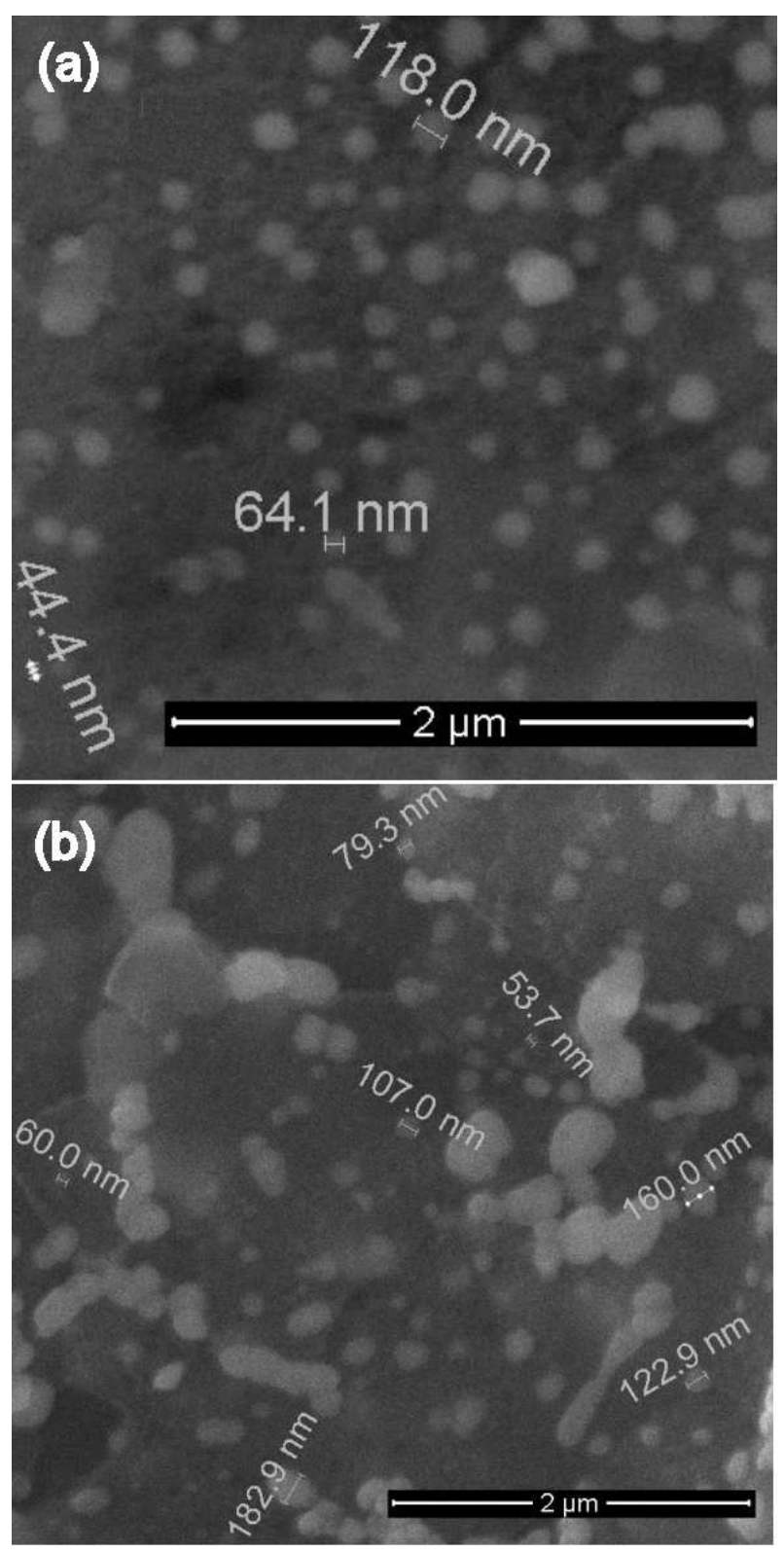

Fig. 4. SEM micrographs of the MCR products: (a) grinding in a mortar, (b) grinding in laboratory mill.

Comparison of diffraction patterns presented in Fig. 2a and Fig. 3a with Fig. 2b and Fig. 3b suggest that there are no significant difference between results obtained in a mortar $\left(z=z_{2}\right)$ and laboratory mill $\left(z=z_{1}\right)$. Differences were noted in proportions of system components and also in some extent in the course of DSC curves presented in Fig. 3a and Fig. 3b, especially in the temperature range about $220-330^{\circ} \mathrm{C}$. In this range of temperatures the DSC curve exhibits two exothermic peaks in Fig. 3b, while one exothermic and one endothermic peak are observed in Fig. 3a. Figure $2 \mathrm{a}$ and $\mathrm{b}$ shows that the ratio of reflex intensity $(I)$ of product components and diluent $\left(I(\mathrm{AgCl}) / I\left(\mathrm{NH}_{4} \mathrm{NO}_{3}\right)\right.$ depend on dilution parameters and their ratio. 


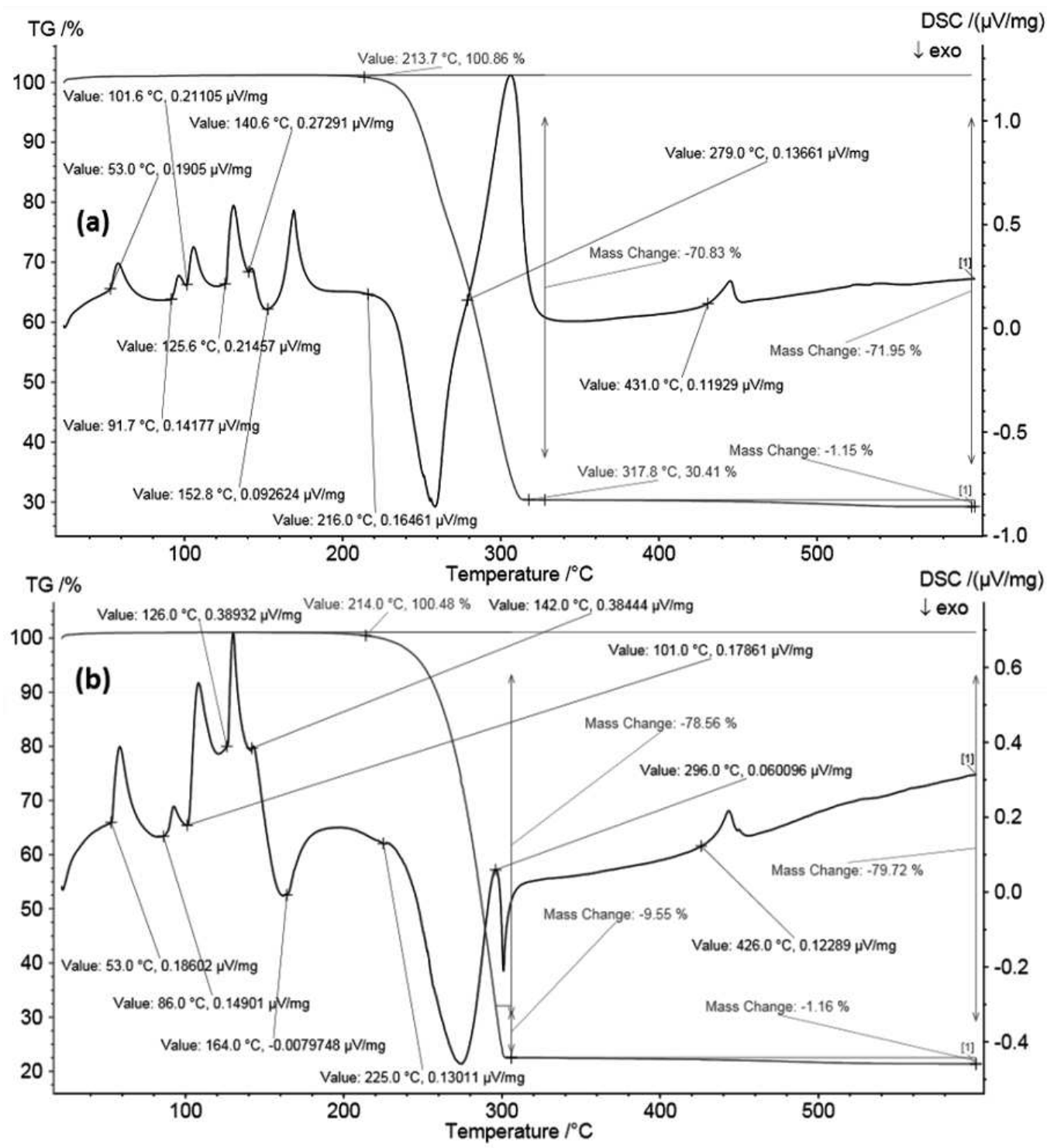

Fig. 3. TG/DSC curves of samples after MCR: (a) grinding in a mortar, (b) grinding in laboratory mill.

The SEM images suggest formation of silver chloride particles with various size distribution lie in the range from $40 \mathrm{~nm}$ to $200 \mathrm{~nm}$. These results correlated with results obtained from XRD measurements. Scanning electron micrographs indicate that particle distribution prepared at different dilution parameters $\left(z=z_{2}=\right.$ 3.64, Fig. 4a, and $z=z_{1}=7.22$, Fig. $4 \mathrm{~b}$ ), have the same surface morphology, however the SEM micrographs scale suggests that the powder at $z=z_{2}$ is more dispersive than in the case at $z=z_{1}$.

A comparison of thermal analysis presented in Fig. 3 shows that the mass loss for $z=z_{1}$ (mass loss before melting point of $\mathrm{AgCl}$ is $70.83 \%$, after melting - $71.95 \%)$ is higher than that for $z=z_{2}(78.56 \%$, $79.72 \%$, respectively). The results suggest that formation of minor amount of silver by using thermal treatment can occur along with major product $(\mathrm{AgCl})$ due to decomposition of starting component and intermediate compound. Preparation of $\mathrm{AgCl}$ in its free form by thermal treatment requires the displacement reaction $\mathrm{NH}_{4} \mathrm{Cl}+\mathrm{AgNO}_{3}+z \mathrm{NH}_{4} \mathrm{NO}_{3}=(z+1) \mathrm{NH}_{4} \mathrm{NO}_{3}+\mathrm{AgCl}$ to go to completion.

\section{Conclusion}

Nanoparticles of silver chloride dispersed within a soluble salt matrix were synthesized by means of powders grinding in a mortar $\left(z=z_{2}=3.64\right)$ and in rotating laboratory mill $\left(z=z_{1}=7.22\right)$ via reaction $\mathrm{NH}_{4} \mathrm{Cl}+\mathrm{AgNO}_{3}+z \mathrm{NH}_{4} \mathrm{NO}_{3}=$ $(z+1) \mathrm{NH}_{4} \mathrm{NO}_{3}+\mathrm{AgCl}$. The synthesis of silver chloride by soft mechanochemical reaction, revealed by XRD, find that the sizes $(L)$ of synthesized particles are $L\left(z_{2}\right)=$ $132 \mathrm{~nm}, L\left(z_{1}\right)=151 \mathrm{~nm}$. The SEM examination of the reaction products suggests the formation of silver chloride particles with wide ranges of size distribution, commonly less than $200 \mathrm{~nm}$. Thermal analysis allowed identification of the optimal temperature range to yield nanoparticles of a desired phase. 


\section{References}

[1] N.L. Hawari, M.R. Johan, J. Alloys Comp. 509 , 2001 (2011).

[2] M.R. Johan, T.S. Leng, N.L. Hawari, S. Suan, Int. J. Electrochem. Sci. 6, 6235 (2011).

[3] D.B. Mohan, C.S. Sunandana, J. Phys. Chem. Solids 65, 1669 (2004).

[4] P.G. McCormick, T. Tsuzuki, J.S. Robinson, J. Ding, Adv. Mater. 13, 1008 (2001).

[5] P.G. McCormick, T. Tsuzuki, J. Metastable Nanocryst. Mater. 13, 377 (2002).

[6] T. Tsuzuki, Int. J. Nanotechnol. 6, 567 (2009).

[7] A.C. Dodd, P.G. McCormick, J. Metastable Nanocryst. Mater. 15, 545 (2003).

[8] T. Tsuzuki, P.G. McCormick, J. Mater. Sci. 39, 5143 (2004).

[9] F.Kh. Urakaev, Int. J. Computat. Mater. Sci. Surf. Eng. 4, 347 (2011).
[10] M. Achimovičová, E. Godočíková, P. Baláž, J. Kovácč, A. Satka, Rev. Adv. Mater. Sci. 18, 216 (2008).

[11] S. Sompech, A. Nuntiya, Orient. J. Chem. 28, 319 (2012).

[12] F.Kh. Urakaev, V.S. Shevchenko, Z.A. Katranova, T.A. Ketegenov, Materialovedenie (Mater. Sci.) 3, 13 (2007) (in Russian).

[13] F.Kh. Urakaev, Mendeleev Commun. 21, 266 (2011).

[14] B.D. Cullity, Am. J. Phys. 25, 394 (1957).

[15] A.M. Balagurov, D.P. Kozlenko, B.N. Savenko, V.P. Glazkov, V.A. Somenkov, S. Hull, Physica B Condens. Matter 265, 92 (1999).

[16] P.Billik, M. Čaplovičová, Powder Technol. 191, 235 (2009).

[17] E. Zobetz, Monatsh. Chem. 111, 1253 (1980). 